\title{
The geographic determinants of bankruptcy: evidence from Switzerland
}

\author{
Stefan Buehler $\cdot$ Christian Kaiser $\cdot$ Franz Jaeger
}

Accepted: 17 September 2010/Published online: 24 October 2010

(C) Springer Science+Business Media, LLC. 2010

\begin{abstract}
This paper examines the geographic determinants of firm bankruptcy. We employ hazard rate models to study the bankruptcy risk of a firm, allowing for time-varying covariates. Based on a large sample from all geographic areas and the major sectors of the Swiss economy, we find the following main results: (1) Bankruptcy rates tend to be lower in the central municipalities of agglomerations; (2) bankruptcy rates are lower in regions with favorable business conditions (where corporate taxes and unemployment are low and public investment is high); (3) private taxes and public spending at the local level have little impact on bankruptcy rates.
\end{abstract}

Electronic supplementary material The online version of this article (doi:10.1007/s11187-010-9301-8) contains supplementary material, which is available to authorized users.

S. Buehler $(\bowtie)$

University of St. Gallen, IFF-HSG, Varnbüelstr. 19, 9000 St. Gallen, Switzerland

e-mail: stefan.buehler@unisg.ch

C. Kaiser

HSBC, 8 Canada Square, London E14 5HQ, UK

e-mail: christian.kaiser@hsbc.com

F. Jaeger

Executive School of Management, Technology and Law, University of St. Gallen, Holzstr. 15, 9010 St. Gallen,

Switzerland

e-mail: franz.jaeger@unisg.ch
Keywords Bankruptcy · Geography ·

Agglomeration · Religion · Language $\cdot$ Exit

JEL Classifications $\mathrm{C} 41 \cdot \mathrm{R} 10 \cdot \mathrm{Z} 10$

\section{Introduction}

From an economist's point of view, it seems natural to look for economic determinants when it comes to explaining economic outcomes. Yet, it is well-known that focusing on economic determinants alone might lead to an incomplete understanding of important economic outcomes. The 'new economic geography', for instance, highlights that geography plays an important role in explaining economic outcomes (Fujita et al. 1999; Fujita and Krugman 2004), whereas a recent strand of the literature emphasizes that culture may affect economic outcomes in various ways (Guiso et al. 2006, 2009; McCleary and Barro 2006; Tabellini 2008; Fernández and Fogli 2009).

In this paper, we study the role of geography in explaining firm bankruptcy, which is a key indicator of a firm's (low) performance. More specifically, we employ hazard rate models to analyze the bankruptcy risk of a firm, incorporating variables that characterize its geographic environment. Some of these variables directly refer to the firm's location (i.e., the local state or municipality), others represent local business conditions (e.g., corporate tax rates, unemployment, and public investment), and some may be 
viewed as representing local culture (e.g., the official language or the dominating religion). In doing so, we contribute to the analysis of firm survival along two dimensions. First, we focus on bankruptcy rather than exit more generally (which also includes other modes of exit, such as voluntary liquidation or merger). Distinguishing exit modes is important because their determinants may differ substantially (Schary 1991; Buehler et al. 2006; Krueger and von Rhein 2009). Second, we study survival determinants that have received relatively little attention in previous work. In particular, we examine the role of localization and urbanization economies for bankruptcy across a large selection of industries, whereas previous work analyzing urbanization economies has focused on output rather than survival (Neffke et al. 2010), a single industry (Boschma and Wenting 2007), or start-up firms only (Dahl and Sorenson 2010).

In a first step, we derive and specify hypotheses on the potential links between geography and bankruptcy. To do so, we review the relevant strands of the previous literature. We start with the survival literature, which is the obvious source for earlier findings on the determinants of bankruptcy. Somewhat surprisingly, this literature offers little information on the links between geography and bankruptcy. Next, we consider the literature on agglomeration economies, which studies the causes and consequences of the geographic concentration of economic activity. A key prediction of this literature is that bankruptcy rates vary significantly across agglomerations (Hypothesis 1). Next, we review the relevant entrepreneurial literature, which provides competing explanations for the geographic concentration of economic activity and emphasizes that entrepreneurial decisions are key factors in explaining both firm location and exit. This literature provides support for Hypothesis 1 and further suggests that bankruptcy rates should be lower in regions with more favorable business conditions (Hypothesis 2). Finally, we note that the recent debate on the role of culture in explaining economic outcomes suggests that bankruptcy rates might be lower in religious regions (Hypothesis 3), but should not be affected by the local language (Hypothesis 4).

In a second step, we provide an empirical analysis of bankruptcy in Switzerland and confront the above hypotheses with our estimation results. Switzerland is well-suited for analyzing the links between bankruptcy and geography, as it offers substantial geographic, political, and cultural variation on a small scale:

(1) The Swiss Federal Statistical Office (2005) provides data that characterize the country's geographic structure in fine detail. Switzerland is structured into 26 cantons (states), which have remained largely unchanged since 1815 . As of 2000, these cantons comprised 2,896 municipalities, each categorized into one of 22 municipality types-which are aggregated into nine "main types"- according to the so-called "municipality typology". Based on a coreperiphery approach pioneered by Gottman (1980), this municipality typology provides a meaningful classification of municipalities into various variants of urban and rural municipalities. We will discuss this typology in more detail in Sect. 3.1.

(2) Federalism grants regional institutions-i.e., cantons and municipalities-strong competencies in designing and executing economic policy. In particular, cantons and even municipalities enjoy extensive tax autonomy, allowing them to set their own tax rates, decide about regional public spending, and determine a large proportion of public (infrastructure) investment. ${ }^{1}$ As a result, there is considerable variation in key economic variables, such as private tax rates, corporate tax rates, public spending, public investment, unemployment, and growth, both across space and time.

(3) The country is generally regarded as both ethnically and culturally diverse. In Fearon's (2003) ranking of ethnic fractionalization by country, Switzerland ranks second in the group of Western European and North American countries with a value of 0.575 (behind Canada with 0.596, but ahead of Belgium with 0.567). ${ }^{2}$ In this author's ranking of cultural diversity,

\footnotetext{
$\overline{1}$ See Feld and Kirchgässner (2001) for an analysis of income tax competition at the state and local level.

${ }^{2}$ Fractionalization is the most common measure of aggregate ethnic diversity. It is defined as the probability that two individuals selected at random from a country will be from different ethnic groups. Formally, if the shares of ethnic groups are given by $p_{1}, \ldots, p_{n}$, then fractionalization is defined as $F \equiv$ $1-\sum_{i=1}^{n} p_{i}^{2}$ (Fearon 2003, p. 208).
} 
Switzerland ranks third with a value of 0.418 (behind Canada with 0.499 and Belgium with 0.462). ${ }^{3}$ Moreover, it is noteworthy that there are no less than four different official languages (French, German, Italian, and Rhaeto-Romanic).

To study the role of geography in explaining firm bankruptcy, we use an enhanced version of the database employed by Buehler et al. (2005, 2006). Our database includes firm-specific information from the Swiss Business Census 1995, which is a complete inventory count of all firms active in September 1995 (excluding the agricultural sector), and the Dun \& Bradstreet exit database for Switzerland, ranging from January 1994 to December 2000. The database also contains the complete geographic municipality typology provided by the Swiss Federal Statistical Office (2005), as well as variables characterizing the firms' cultural environment, such as the relevant official language and the population shares of the various religious denominations. ${ }^{4}$ Finally, the database comprises various time-varying economic variables reflecting the local business conditions at the cantonal level, including corporate tax rates, unemployment rates, and public investment. Overall, our sample includes more than 74,000 firms from all geographic areas and the major industries of Switzerland.

We estimate bankruptcy rates using both a continuous-time Cox model with time-varying covariates (Van den Berg 2001) and a discrete-time random effects logit model to control for unobserved heterogeneity at the firm level (Jenkins 1995). We find the following key results. First, bankruptcy rates vary significantly across agglomerations. In a simple specification, where we use the standard variables of the survival literature plus a set of cantonal dummies to control for geographic location, we find evidence for considerable variation in bankruptcy rates across cantons. In a refined specification, where we employ the main municipality types and other variables

\footnotetext{
$\overline{3 \text { To measure }}$ cultural diversity, Fearon (2003) defines a resemblance factor $r_{i j} \in[0,1]$ for two ethnic groups $i$ and $j$, which is zero if the groups' languages come from completely different families and one if the groups speak the same language. Cultural diversity is then defined as $D \equiv 1-$ $\sum_{i=1}^{n} \sum_{j=1}^{n} p_{i} p_{j} r_{i j}$.

${ }^{4}$ The Roman Catholic Church and the Evangelic Reformed Church are the dominating religious denominations in Switzerland (see Sect. 3.2 for further details).
}

(rather than cantonal dummies) to characterize geographic location, we find that bankruptcy rates in central and touristic municipalities are significantly lower than those in suburban municipalities (but not significantly different from those in other types of municipalities). Since central and touristic municipalities typically form the centers of metropolitan and non-metropolitan agglomerations, respectively, we conclude that bankruptcy rates tend to be lower in the central municipalities of agglomerations. This finding is consistent with both the agglomeration and the entrepreneurial literature.

Second, bankruptcy rates are lower in regions with favorable business conditions where corporate taxes and unemployment are low and public investment is high. At first glance, this result may appear natural. Note, however, that the effect of unemployment on bankruptcy rates, for instance, is not clear-cut: due to lower opportunity costs, unemployed workers may be induced to create less productive firms which are more likely to fail than those founded by employed workers; alternatively, one could argue that firms can benefit from hiring unemployed workers at lower cost and should therefore be less likely to fail. In line with earlier work, our estimates suggest that the first argument is more important.

Third, both private taxes and public spending at the local level have little impact on bankruptcy rates. That is, local business conditions are not found to be significantly affected by the level of private taxation and public spending.

In sum, our results indicate that geography contributes significantly to the explanation of bankruptcy rates. It is worth noting, though, that the results for the standard determinants of firm survival remain valid even after extending the analysis to the realm of geography. In particular, we confirm that bankruptcy rates are decreasing in firm size (except for very small firms) and firm age, and our results for other standard survival determinants (such as legal form or export activity) are also in line with earlier work.

The remainder of the paper is structured as follows. Section 2 derives and specifies hypotheses on the links between geography and bankruptcy. Section 3 provides some background information on the geography of Switzerland. Section 4 describes the dataset and the key variables. Section 5 sets out the empirical models and discusses our main results. Section 6 concludes the paper. 
Table 1 Hypotheses

(1) Bankruptcy rates vary significantly across agglomerations

(a) Bankruptcy rates are lowest in agglomerated cantons with international airports

(b) Within agglomerations, bankruptcy rates are lowest in central municipalities

(2) Bankruptcy rates are lower in regions with favorable business conditions

(a) Unemployment has a positive impact on bankruptcy rates

(b) Corporate taxation has a positive impact on bankruptcy rates

(c) Public investment has a negative impact on bankruptcy rates

(3) Bankruptcy rates are lower in religious regions

(4) Bankruptcy rates are not affected by regional languages

\section{Linking bankruptcy to geography}

In this section, we discuss the links between bankruptcy and geography that have been studied in different strands of the literature. We start with the survival literature, which is the obvious source for earlier findings on the geographic determinants of bankruptcy. Next, we consider the literature on agglomeration economies, which examines how geographic agglomerations affect firm performance, and we consult the entrepreneurial literature, which provides a number of competing explanations for geographic concentration and emphasizes the role of the entrepreneur in making firm decisions. Finally, we discuss the extent to which the cultural characteristics of geographic regions might play a role in explaining bankruptcy.

Table 1 summarizes the hypotheses that emanate from our discussion of the various strands of literature in Sects. 2.1-2.4.

\subsection{Survival}

The survival literature has largely focused on firmand industry-specific characteristics as well as on the relevant macroeconomic conditions as potential determinants of exit. ${ }^{5}$ Van Kranenburg et al. (2002)

\footnotetext{
5 It is well known that exit rates vary considerably across industries. Dunne et al. (1988), for instance, report substantial and persistent differences in exit rates across U.S. manufacturing industries. There are a number of potential explanations
}

survey this literature and provide an empirical analysis that treats these characteristics in an integrated way. There is a small number of studies analyzing exit behavior across geographic regions. Fotopoulos and Louri (2000), for instance, study a sample of 209 new firms in Greece, finding that firms located in the greater Athens area face an increased chance of survival compared to firms located in the rest of Greece. Berglund and Brännäs (2001) examine plants' entry and exit behavior in 283 Swedish municipalities, finding relevant variation in exits across municipalities. Using plant-level data, Dunne et al. (2005) analyze exit from seven regional manufacturing industries in the USA. These authors find that a producer's experience in related geographic or product markets at the time of entering a market affects both the overall probability of exit and the mode of exit (i.e., plant shutdown vs. product-line exit). Glauben et al. (2006) study exit rates in agriculture across 326 counties in Western Germany. They find significant differences in the exit rates of farms across regions. Buehler et al. (2006) compare the determinants of bankruptcy and merger rates in Switzerland. They find considerable differences in bankruptcy and merger rates across regions, with bankruptcy (merger) rates being highest (lowest) in the southern part of Switzerland. Taken together, these studies suggest that there is a link between a firm's bankruptcy risk and its geographic location, but they provide little information on the nature of this link.

\subsection{Agglomeration economies}

There is a broad consensus that, on average, firms and workers in large and dense urban environments are more productive. ${ }^{6}$ The urban economics and geography literature discusses three different types of externalities that may explain this productivity difference (cf. Neffke et al. 2010). First, firms in agglomerations may benefit from within-industry

\footnotetext{
Footnote 5 continued

for such differences, including the intensity of competition (Symeonidis 2002), the industry life cycle (Mata et al. 1995; Agarwal and Gort 1996), and the speed of innovation (Geroski 1995; Audretsch 1995; Segarra and Callejón 2002).

${ }^{6}$ See Puga (2010), Melo et al. (2009), and Rosenthal and Strange (2004) for recent surveys.
} 
localization externalities arising from labor market interactions, knowledge spillovers, and specialized inputs (Duranton and Puga 2004; Buenstorf and Klepper 2009; Puga 2010). ${ }^{7}$ Second, agglomerations may generate so-called Jacobs' externalities (Jacobs 1969; Glaeser et al. 1992; Duranton and Puga 2001) relating to the benefits of having a high level of industrial diversity in an agglomeration. Third, firms may benefit from urbanization externalities which capture the advantages of operating in a large city, such as having access to large markets, modern infrastructure, and highly educated employees.

Related work by Melitz (2003) and Melitz and Ottaviano (2008), which studies product differentiation and inter-regional trade with endogenous pricecost margins, suggests that the productivity differences might also be explained by firm selection. The underlying idea is that larger markets attract more firms, which makes competition tougher and forces the less productive out of the market. Combes et al. (2009) combine these two approaches by nesting an agglomeration model with a generalized firm selection model. These authors find that stronger selection in larger cities left-truncates the firms' productivity distribution, whereas stronger agglomeration economies right-shift and dilate the distribution. They also show that productivity differences in France are mostly explained by agglomeration economies.

What are the implications of this literature for the analysis of firms' bankruptcy risk? Allowing for permanent productivity shocks at the firm level, Buenstorf and Klepper (2009) show that firms located in regions with greater agglomeration economies face lower exit hazard rates. Intuitively, the result follows from the fact that the higher productivity of firms located in more agglomerated regions makes them less vulnerable to negative shocks. Therefore, if bankruptcy rates and exit rates are positively correlated, we should expect bankruptcy rates in more agglomerated regions to be lower. ${ }^{8}$ Note, however, that agglomerated areas typically differ in the extent

\footnotetext{
7 These economies are also known as Marshall-Arrow-Romer (MAR) externalities.

${ }^{8}$ The firm selection effect tends to work in the opposite direction: Due to the left-trunction of the firms' productivity distribution, even firms with relatively high productivity become vulnerable to negative productivity shocks.
}

to which they offer the various types of externalities discussed above, suggesting that firm productivities are likely to vary across different types of agglomerations.

With this in mind, we hypothesize that bankruptcy rates vary significantly across agglomerations (cf. Hypothesis 1 in Table 1). More specifically, in terms of the variation of bankruptcy rates across cantons, we hypothesize that bankruptcy rates are lowest in the most agglomerated cantons with international airports (i.e., the cantons of Zurich and Geneva), where firms are likely to benefit the most from positive externalities (Hypothesis 1a). Similarly, in terms of the variation of bankruptcy rates across municipality types, we hypothesize that bankruptcy rates are lowest in the central municipalities of (metropolitan and non-metropolitan) agglomerations (Hypothesis 1b).

\subsection{Entrepreneurship}

\subsubsection{Entrepreneurial view of agglomeration}

The entrepreneurial literature provides various competing explanations for agglomeration. Sorenson and Audia (2000), for instance, argue that heterogeneity in entrepreneurial opportunities rather than differential firm performance maintains geographic concentration. The underlying idea is that successful entrepreneurs need exposure to established organizations to acquire tacit knowledge and build social ties as well as self-confidence. As a result, the foundation of new firms tends to reinforce the geographic concentration of industries. These authors argue that agglomerations are sustained by higher founding rates, not lower failure rates. In their study of footwear production in the USA, they find that plants in dense locations experienced higher failure rates than more isolated plants.

In a related paper, Shaver and Flyer (2000) emphasize that heterogeneous firms differ in the extent to which they benefit from agglomeration economies. Specifically, they argue that agglomeration processes are characterized by adverse selection, because marginal firms have little to lose from outward spillovers and much to gain from inward spillovers and thus have a strong incentive to cluster geographically. The best firms, in turn, have little incentive to cluster because they gain little from 
inward and lose much from outward spillovers among firms. They provide supportive evidence for foreign greenfield investments in U.S. manufacturing industries. $^{9}$

Klepper (2007) explains the agglomeration of the U.S. automobile industry around Detroit, Michigan, referring to a theory by Klepper and Thompson (2007) which posits that disagreements with management lead employees of incumbent firms to found spin-offs in the same industry. This theory suggests that experienced firms and spin-offs of incumbent firms are better able to deal with technological change than inexperienced firms and thus face lower hazard rates. Klepper's (2007) empirical findings are consistent with this prediction. Buenstorf and Klepper (2009) provide a related heritage explanation for the agglomeration of the U.S. automobile tire industry in Akron, Ohio.

Analyzing the determinants of entrepreneurs' choices of where to locate, Dahl and Sorenson (2009, 2010) allude to embedded entrepreneurs, who place more emphasis on being close to family and friends than on regional characteristics that might affect the profitability of their ventures. Their findings support the view of agglomeration as a selfenforcing process in densely populated regions.

In sum, this strand of the literature challenges the robustness of the agglomeration literature's results and provides alternative mechanisms through which agglomeration comes about. They also underline the usefulness of testing whether bankruptcy rates vary significantly across agglomerations (Hypothesis 1 in Table 1).

\subsubsection{Entrepreneurial choice and exit rates}

Earlier work by Love (1996a, b) suggests a simple model of entrepreneurial choice to explain the variation in exit rates across regions, where each individual compares expected earnings from employment with expected profits from running a business. He argues that local income or average local wages should be viewed as key determinants of exit

\footnotetext{
9 Alcácer and Chung (2007) further highlight that firms not only gain from inward knowledge spillovers, but also suffer from outward spillovers. Analyzing U.S. data, they find that technologically advanced firms tend to avoid locations with industrial activity to distance themselves from competitors.
}

decisions, as "most firms are geared towards serving the local area" (Love 1996a, p. 108). Moreover, he claims that the likelihood of exit is largely determined by how favorable conditions are for businesses primarily relying on local demand. The latter reasoning is in line with Lane and Schary's (1991) finding that local business conditions were the key determinants of variations in business failures across states in the USA. This approach suggests the hypothesis that bankruptcy rates are lower in regions with favorable business conditions (cf. Hypothesis 2 in Table 1).

Hypothesis 2 raises the question of what determines the favorability of local business conditions. Local unemployment is often viewed as a key indicator of how favorable local business conditions are. It is worth noting, however, that the effect of unemployment on bankruptcy rates is not clear-cut. Following Hudson (1989) and Evans and Leighton (1990), it is sometimes argued that-due to lower opportunity costs-unemployed workers will be more likely to create new firms than employed workers and that these firms tend to be less competitive, so that they are more likely to fail. This line of argument suggests that unemployment should have a positive impact on bankruptcy rates. ${ }^{10}$ Alternatively, one could argue that, from a firm's point of view, conditions in the labor market are favorable if unemployment is high, as firms can then hire employees at relatively low cost. This view would suggest that unemployment has a negative impact on bankruptcy rates. Despite these ambiguities, Everett and Watson (1998) consistently find (allowing for different types of exit) that unemployment has a positive impact on exit rates. In line with these findings, we hypothesize that unemployment has a positive impact on bankruptcy rates (cf. Hypothesis 2a in Table 1).

Local business conditions should also be expected to be affected by local economic policy. As noted above, federalism grants cantons and municipalities strong competencies in designing and executing economic policy. Key instruments of public policy at the local level include the taxation of individuals and firms as well as public spending and investment. It is natural to hypothesize that corporate taxation has

\footnotetext{
${ }^{10}$ Note that a reversed chain of causation, where firm exits lead to increases in unemployment, would also lead to a positive relation between exit rates and unemployment.
} 
a positive impact on bankruptcy rates (Hypothesis $2 \mathrm{~b}$ in Table 1), whereas public investment should have a negative impact (Hypothesis 2c).

\subsection{Geography and culture}

Even though the debate on the role of culture in explaining economic outcomes has a fairly long history (see Guiso et al. 2006; McCleary and Barro 2006 for surveys), economists seem to have ignored the role of culture in explaining bankruptcy: We are not aware of a single contribution on the cultural determinants of bankruptcy. However, if we follow Guiso et al. (2006, p. 23) in defining culture as

those customary beliefs and values that ethnic, religious, and social groups transmit fairly unchanged from generation to generation,

it is natural to expect that culture not only varies across regions but that it also affects bankruptcy rates. In line with McCleary and Barro (2006, p. 51), we will take what could be called a "Weberian perspective", assuming that religious beliefs can raise the productivity of workers "by fostering traits such as honesty, work ethic and drift." That is, assuming that potential entrants are heterogenous in capabilities but similarly affected by the higher productivity of religious workers, we expect more entry ${ }^{11}$ and higher average firm productivity in religious regions. Following Buenstorf and Klepper (2009), we therefore expect bankruptcy rates to be lower in religious regions (Hypothesis 3) with stochastic profitability shocks (see Sect. 2.2).

Another well-known proxy of a region's culture is its official language. However, there is arguably no clear-cut relation between a region's official language and its bankruptcy rate. From a Weberian perspective, a variation in bankruptcy rates across linguistic regions could perhaps be explained by differences in work ethic or thrift. Alternatively, it might be explained by unobserved differences in firm quality or risk aversion which are picked up by the language proxy. We are nevertheless going to hypothesize that bankruptcy rates are not affected by regional languages (Hypothesis 4).

\footnotetext{
11 Using data from India, Audretsch et al. (2007) document the impact of religion on the decision of people in India to become entrepreneurs.
}

\section{Some geographical aspects of Switzerland}

\subsection{Regional institutions: cantons and municipalities}

Covering roughly 41,000 square kilometers, Switzerland is a comparably small federal state in Western Europe. The country consists of 26 cantons and 2,896 municipalities (as of 2000). Since the end of the Viennese congress in 1815 , the territory has remained largely unchanged. Similarly, the internal structure has been very stable during the last decades, and despite considerable differences (e.g., regarding expansion and population), ${ }^{12}$ all cantons share the same legal status. Figure S1 in the electronic supplementary material (ESM) shows the 26 cantons and their capital cities.

As noted above, federalism grants the cantons a lot of freedom in designing and executing their own policies, including economic policy. This is reflected in a considerable variation in private and corporate tax rates, public spending and investment as well as unemployment and growth-both across cantons and over time. Cantons also differ widely in terms of their population and industry structures, even though these structures appear to vary less over time. In our empirical study described in the followed section, we shall exploit the variation across space and time.

The cantons themselves are structured into varying numbers of municipalities. The canton of Berne, for example, consists of 400 municipalities, whereas the canton of Basel-Stadt comprises merely three municipalities (Swiss Federal Statistical Office 2005). Again, the characteristics of these municipalities vary greatly. The Swiss Federal Statistical Office (2005) provides a systematic characterization of each single municipality, based on a particular "coreperiphery" approach derived by Gottman (1980). This characterization-also called "municipality typology"-associates each municipality with one of 22 municipality types. These types are then aggregated by the Federal Statistical Office into the nine "Main Municipality Types" listed in Table 2.

The categorization of municipalities into 22 municipality types follows from a set of hierarchically related criteria. If a particular municipality

\footnotetext{
$\overline{12}$ For instance, the population ratio of the largest and the smallest canton is $85 / 1$. The expansion ratio amounts to $192 / 1$.
} 
Table 2 Main municipality types, 2000

\begin{tabular}{llcc}
\hline Type & Description & $\begin{array}{l}\text { Number of } \\
\text { communities }\end{array}$ & Percentage \\
\hline (1) & Center & 69 & 2.4 \\
(2) & Suburban & 332 & 11.5 \\
$(3)$ & Affluent & 88 & 3.0 \\
$(4)$ & Periurban & 464 & 16.0 \\
$(5)$ & Touristic & 164 & 5.7 \\
$(6)$ & Industrial \& & 349 & 12.1 \\
(7) & Tertiary & & \\
$(8)$ & Rural Commuting & 632 & 21.8 \\
(9) & Agrarian Mixed & 494 & 17.1 \\
& Agrarian & 304 & 10.5 \\
\hline
\end{tabular}

Source: Swiss Federal Statistical Office (2005, p. 126)

satisfies the criteria of several municipality types, it is associated with the "dominant" type (Swiss Federal Statistical Office 2005, p. 118). This categorization can be illustrated for the municipality of St. Moritz, which at first glance might be classified as a touristic or an affluent municipality; however, in the official categorization, St. Moritz is classified as (1) the core city of agglomeration $3787,{ }^{13}$ (2) a municipality with tertiary function of touristic character (municipality type 6), and (3) a touristic municipality (main type 5). Key criteria for determining this classification are the tax revenues from private individuals per resident and the number of touristic overnight stays. ${ }^{14}$

The main type Center is made up of large, medium, and small municipalities, which form the center of large agglomerations in metropolitan regions. The Suburban type contains both suburban municipalities and job-rich municipalities in metropolitan regions which do not qualify as centers of agglomerations. The Affluent type contains municipalities with real income per resident exceeding some specific threshold level. The Periurban type collects municipalities that are located in an agglomeration but do not qualify as suburban or affluent communities.

\footnotetext{
13 Note that agglomeration 3787 is not a metropolitan agglomeration, such that St. Moritz does not qualify as a central municipality.

14 A more detailed discussion of the categorization into municipality types and the process of aggregation into main types is beyond the scope of this paper. See Swiss Federal Statistical Office (2005, p. 115) for further details.
}

The Touristic type contains municipalities that feature a high number of touristic overnight stays. The Industrial \& Tertiary type collects municipalities where the production of industrial goods and services is particularly high, including periphery centers. The Rural Commuting type contains municipalities outside agglomerations where the share of people commuting to workplaces elsewhere is above some specific threshold level. The Agrarian Mixed and the Agrarian type collects municipalities with a relatively high share of agrarian production.

Table 2 indicates that almost half of the municipalities are classified as predominantly rural or agrarian [main types (7), (8), or (9)]. The number of touristic and affluent municipalities [types (3) and (5)] is comparably small. Figure S2 of the ESM provides a map showing the distribution of the main municipality types across the country.

According to Hypothesis 1b, bankruptcy rates are lowest in the central municipalities of agglomerations. We should therefore expect bankruptcy rates to be lowest for the main type Center.

\subsection{Regional culture: religion and language}

As mentioned above, there is a considerable amount of cultural heterogeneity across regions. Regarding religious denominations, it is important to note that there is no country-wide state religion. Table 3 provides the population shares of the various religious denominations and their respective roles in the four linguistic regions. The Catholic and the Evangelic Reformed Church are the most common religious denominations in all four linguistic regions. The third-largest group of the population is not affiliated with any religious denomination. Relatively large groups of the population further adhere to the Islamic Confraternities and the Eastern Orthodox Church. Figure S3 of the ESM provides a map showing the concentration of the Catholic and the Reformed Evangelic Church at the municipality level. In rural areas, the majority of the population traditionally tends to adhere to the Roman Catholic Church, whereas in agglomerations, the Evangelic Reformed Church tends to dominate. Yet, migration has somewhat relaxed this pattern, and there is now a considerable number of communities where more than $60 \%$ of the population adhere to neither the Catholic nor the Evangelic Reformed Church. 
Table 3 Religious denominations as a share (percentage) of the population and according to linguistic regions, 2000

\begin{tabular}{|c|c|c|c|c|c|}
\hline \multirow[t]{2}{*}{ Religious denomination } & \multicolumn{4}{|c|}{ Linguistic region } & \multirow[t]{2}{*}{ Total $(\%)$} \\
\hline & German & French & Italian & Rhaeto-Romanic & \\
\hline Evangelic Reformed Church & 37.41 & 24.86 & 6.05 & 28.90 & 33.04 \\
\hline Evangelic Methodist Church & 0.15 & 0.02 & 0.01 & 0.02 & 0.12 \\
\hline New Pietist Evangelic Congr. & 0.54 & 0.20 & 0.08 & 0.25 & 0.44 \\
\hline Pentecostalism & 0.30 & 0.23 & 0.12 & 0.05 & 0.28 \\
\hline New Apostolic Church & 0.47 & 0.15 & 0.14 & 0.11 & 0.38 \\
\hline Jehova's Witnesses & 0.26 & 0.29 & 0.54 & 0.05 & 0.28 \\
\hline Other Protestant Churches & 0.66 & 1.01 & 0.19 & 0.10 & 0.72 \\
\hline Roman Catholic Church & 38.30 & 45.79 & 76.11 & 62.61 & 41.82 \\
\hline Old Catholic Church & 0.20 & 0.12 & 0.18 & 0.07 & 0.18 \\
\hline Christian Orthodox Churches & 1.95 & 1.32 & 2.28 & 0.79 & 1.81 \\
\hline Other Christian Confraternities & 0.19 & 0.24 & 0.08 & 0.06 & 0.20 \\
\hline Jewish denomination & 0.20 & 0.41 & 0.12 & 0.01 & 0.25 \\
\hline Islamic Confraternities & 4.66 & 3.56 & 1.84 & 1.14 & 4.26 \\
\hline Buddhistic aggregations & 0.32 & 0.25 & 0.14 & 0.02 & 0.29 \\
\hline Hindu aggregations & 0.46 & 0.21 & 0.14 & 0.04 & 0.38 \\
\hline Other churches and religions & 0.10 & 0.16 & 0.04 & 0.04 & 0.11 \\
\hline No affiliation & 10.25 & 14.54 & 7.33 & 3.10 & 11.11 \\
\hline No answer & 3.57 & 6.62 & 4.62 & 2.63 & 4.33 \\
\hline Total $(100 \%)$ & $5,221,135$ & $1,720,365$ & 320,247 & 26,263 & $7,288,010$ \\
\hline
\end{tabular}

Source: Swiss Federal Statistical Office (2004, p. 111)

According to Hypothesis 3, bankruptcy rates are lower in religious regions. To proxy how religious a particular region might be, we employ the joint share of the (traditionally) dominating religious denominations (the Roman Catholic Church and the Evangelic Reformed Church) at the cantonal level. Specifically, we expect bankruptcy rates to be lower in regions with higher shares of the dominating religious denominations. ${ }^{15}$

Figure S4 of the ESM provides a map of the four different linguistic regions. Inspection indicates that German and French are the most common languages, followed by Italian and Rhaeto-Romanic (see also Table 3). Note that the borders of linguistic regions do not necessarily coincide with the border of cantons. In fact, some cantons are well-known for being bilingual or even trilingual. ${ }^{16}$

\footnotetext{
$\overline{15}$ In our estimates below, all other religious denominations are pooled in the reference group OtherRel (in which "No Affiliation" dominates, see Table 3).

16 Numerous other (non-official) languages are being spoken by subgroups of the population in each canton, including English, Serbian, Croatian, Albanian, and Turkish.
}

According to Hypothesis 4, bankruptcy rates should not be affected by regional languages. We will test this hypothesis below using the data on the linguistic regions.

\section{Data and variables}

In this section, we describe our dataset and the most important variables used for the analysis of the determinants of firm bankruptcy.

\subsection{Sample composition}

For the purpose of this study, we merged the following three databases:

(i) The Business Census (BC 95). The $\mathrm{BC} 95$ is a complete inventory count of all firms with more than 20 weekly aggregate working hours in September 1995, excluding the agricultural sector. It is compiled by the Federal Statistical Office and contains numerous variables characterizing 
the attributes of these firms as of September 1995, including their size, age, and legal form. Importantly, the database also contains the firms' host municipality, which allows us to characterize their geographic location using the municipality typology described in Sect. 3.1. ${ }^{17}$

(ii) The Dun \& Bradstreet Exit Database (DBED). The DBED provides all bankruptcies of firms registered in Switzerland from January 1994 to December 2000.

(iii) The Spatial Structure of Switzerland (SSS). As noted above, the SSS provides a geographic characterization of each municipality into one of nine main types. Moreover, it contains rich information on various other aspects of the spatial structure.

In addition to these databases, we collected data from various other official sources, including the Federal Fiscal Authority and the Swiss National Bank.

The observation period of the merged database ranges from October 1995 to December 2000. In line with previous studies, we deleted all firms that were non-profit oriented according to their legal status (such as cooperatives, associations, foundations, churches, and international organizations), reducing the number of firms to roughly 276,000 . In addition, we dropped (1) all sole proprietorships (since the DBED covers their bankruptcies incompletely) and (2) all firms established before 1970, due to the lack of information on their founding dates. Even after dropping these firms, the merged database is still comprehensive and includes roughly 74,000 singleand multi-plant firms. More specifically, our sample comprises firms of all sizes that have been in business up to 25 years. With the exception of agriculture, our sample includes all major industries, including services. Crucially, our sample comprises firms from all main municipality types.

We are aware of a number of drawbacks of our database. First, the database is based on a firm census from September 1995, which implies that the firm

\footnotetext{
17 The majority of firms in our sample are single-plant firms. Multi-plant firms are associated with the municipality of their headquarters. We are well aware, though, that the bankruptcy risk of a large-perhaps multi-national-firm is unlikely to be determined by the characteristics of their headquarters' host community.
}

characteristics we use are time invariant, even though some firm characteristics may have changed since 1995. This is a common limitation of survival analyses (see, for example, Harhoff et al. 1998). ${ }^{18}$ Second, our sample does not provide information on firm entry after 1995, even though previous work emphasizes the correlation of entry and exit rates at the industry level (see, for example, Geroski 1995; Caves 1998). This limitation is due to the lack of entry data at the firm level. Since the covariates under study may affect both bankruptcy and entry, our hypotheses in Table 1 presuppose that regional differences are not fully dispersed by differential entry. Third, the database does not allow us to distinguish between independent firms and firms that belong to larger groups of companies. However, since our focus is on the impact of an individual firm's geographic environment on its performance, we do not believe this is a major drawback.

We now discuss some special properties of our sample. The descriptive statistics in Table A1 in the Appendix-ESM indicate that small firms make up a large proportion of our sample. Using the number of employees (Emp) to measure firm size, average firm size is at about 11 employees (the median is even lower). Moreover, since firms founded before 1970 had to be excluded from the sample, firms were on average relatively young (i.e., $<10$ years) when they entered the survey period. Finally, it is worth noting that roughly two thirds of the firms in our sample belong to the service sector, whereas earlier studies typically had limited access to data on firms in the service sector.

\subsection{Variables and descriptive statistics}

We first explain the construction of our dependent variable - a firm's lifetime - and then discuss the explanatory variables. Table A1 in the AppendixESM summarizes the descriptive statistics.

\subsubsection{Dependent variable}

Our dependent variable is a firm's lifetime, measured by how many quarters a firm has stayed in business (Duration). The database records a bankruptcy if a

\footnotetext{
18 Note, however, that many other covariates in our study are time variant (see Table A1 in the Appendix-ESMl).
} 
Table 4 Summary of spells

Source: DBED, Swiss Federal Statistical Office; own calculations

\begin{tabular}{llcc}
\hline Type & Description & Number of firms & Percentage \\
\hline$(1)$ & Bankruptcy & 4,555 & 6.1 \\
$(2)$ & Censored (merger, voluntary liquidation) & 6,700 & 9.0 \\
$(3)$ & Right-censored & 63,317 & 84.9 \\
& Total & 74,572 & 100.0 \\
\hline
\end{tabular}

firm filed for bankruptcy between October 2, 1995, and December 31, 2000. For the exact date, we use the first available date which, in the bulk of cases, is when the court initiated bankruptcy proceedings. Using the time of foundation ${ }^{19}$ and the time of bankruptcy, it is straightforward to calculate the duration of a firm's lifetime. The mean (median) duration of survival is 54 quarters (47 quarters, respectively). Table 4 provide a summary of the spells in our dataset.

Table 4 shows that roughly $6 \%$ of the firms became insolvent during the survey period, $9 \%$ are censored due to merger or voluntary liquidation (i.e., other modes of exit), and almost $85 \%$ are rightcensored: for the firms that have not left the pool during the survey period, the true duration is at least as large as the observed duration. In addition, the data is left-truncated, because firms must have been founded prior to October 1995 and survived up to this date to be included into the census (delayed entry). ${ }^{20}$ In our estimations below, we control for lefttruncation by conditioning on survival up until the truncation date (i.e., the beginning of the survey), and we account for censoring.

\subsubsection{Explanatory variables}

4.2.2.1 Firm attributes Since our study is based on a firm census, all firm attributes refer to the date when the firm filed for the business census (in September 1995) and are time invariant. Following previous literature (see, for example, Brüderl et al. 1992; Audretsch 1995; Harhoff et al. 1998), we operationalize firm size by the log of the number of employees (LnEmp). We also include the square of this variable $\left[(L n E m p)^{2}\right]$ to allow for non-monotonicity. As an additional proxy, we use the log of the number of

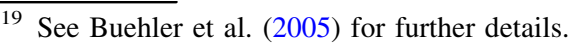

20 The average (median) age at the time of entering the survey was 35 quarters (28 quarters, respectively).
}

apprentices $(L n A p p){ }^{21}$ The latter variable may be viewed to reflect a firm's expectation of its future success: a large firm that does not employ apprentices signals that it is not willing to spend resources for longterm development and focuses instead on short-term survival. In line with previous work (see, for example, Freeman et al. 1983), we also control for a firm's age, employing the log of a firm's age at the time of entering the survey (LnAge).

The legal form of firms is classified into four groups differing with respect to initial capital requirement (Brüderl and Schüssler 1990), ease of ownership transfer and liability rules (Harhoff et al. 1998) as well as tax treatment: (1) Partnerships (Partner), (2) limited liability companies (Lim Liab), and (3) stock corporations (Stock Corp). The fourth legal form, sole proprietorships, was dropped because the DBED incompletely covers the bankruptcies of sole proprietorships (see Sect. 4.1). Throughout the study, we use Partner as the reference variable.

Another important firm attribute is the export share of a firm. This share is calculated as the ratio of a firm's exports over its turnover. The BC 95 distinguishes four groups of firms: (1) non-exporting (Export_1), (2) exporting less than one-third of the turnover (Export_2), (3) exporting between one-third and twothirds (Export_3), and (4) exporting more than twothirds (Export_4). Here, we use Export_l as the reference variable.

4.2.2.2 Industries Since industries tend to cluster, it is important to account for industry-specific effects when studying the variation in bankruptcy rates across regions. The $\mathrm{BC} 95$ records the industry in which a firm primarily operates. To control for industryspecific effects, we use a series of time-invariant 23 dummy variables which represent the Swiss equivalent

\footnotetext{
$\overline{21}$ Size variables are commonly log-transformed, as it is natural to assume that the marginal effect of size on bankruptcy decreases.
} 
to the two-digit standard international industrial classification (SIC) code. The food industry (Food) serves as the reference variable.

\subsubsection{Macroeconomic conditions Since Switzer-} land is a small open economy, it is crucial to control for changes in the exchange rate of its currency. We use a time-varying index of the currency's external value provided by the Swiss National Bank (2003), which is based on the real exchange rates with the 24 most important trade partners (Ext Val). ${ }^{22}$ As an additional proxy for the aggregate movement of the economy, we employ the aggregate number of bankruptcies from the previous year (Bankrupt). This is in line with previous work by Van Kranenburg et al. (2002), Ranger-Moore (1997), and Roberts and Thompson (2003). ${ }^{23}$

\subsubsection{Cantons and municipalities In a simple} specification, we use cantonal dummies to control for geographic effects at the cantonal level. In this specification, we employ the canton of Zurich (Zurich) as the reference variable. This specification highlights differences in bankruptcy rates across geographic regions.

In a refined specification, we replace the cantonal dummies by a selection of variables to explore the determinants of these differences. First and foremost, we use the much finer municipality typology described in Sect. 3.1 to characterize each firm's geographic location. For this specification, central municipalities (Center) serve as the reference group. Second, we attempt to control for differences in local business conditions at the cantonal level, using timevarying variables. More specifically, we employ the level of private and corporate tax rates (Private Taxes and Public Taxes, respectively), public spending (Public Spend), public investment (Public Invest), unemployment (Unemployment), and the growth rate (Growth). Third, we control for differences in the population structure at the cantonal level, using the lagged migration balance (Migration Bal), ${ }^{24}$ the share

\footnotetext{
${ }^{22}$ Since we use a 1-year lag specification, we use values from 1994 to 1999 for our estimations.

23 The use of dummy variables to proxy for the aggregate movement of the economy caused collinearity problems.

24 That is, we aggregate migration into and out of a given canton.
}

of foreign population (Foreignsh), and the average age of the population (PopAge).

4.2.2.5 Religion and language In an attempt to measure how religious a region might be, we employ the joint share of the (traditionally) dominating religious denominations (the Roman Catholic Church and the Evangelic Reformed Church) at the cantonal level (DomRel). We believe this is a reasonable (if very crude) proxy for the case of Switzerland. The pooled share of the other religious denominations serves as the reference variable (OtherRel).

We also control for the linguistic region in which a firm is located (German, French, Italian). ${ }^{25}$ Here, firms operating in the German-speaking area (German) serve as the reference group.

\section{Empirical models and results}

We use hazard rate models to characterize the probability of a firm's bankruptcy. Let $T_{i}, i=$ $1, \ldots, N$, denote the duration of firm $i$ 's survival in the market, and let $F_{i}(t)=\operatorname{Pr}\left(T_{i} \leq t\right)$ be the distribution function determining the probability that firm $i$ exits before time $t \geq 0$, with corresponding density function $f_{i}(t)$. Similarly, let $S_{i}(t)=\operatorname{Pr}\left(T_{i}>t\right)=$ $1-F_{i}(t)$ denote the survival function.

In the following subsections, we first provide Kaplan-Meier survival estimates for various subsamples of our dataset and then analyze the determinants of bankruptcy using hazard rate models.

\subsection{Kaplan-Meier survival estimates}

The Kaplan-Meier estimator provides a non-parametric estimate of the survival function at time $t$. For survival durations ordered such that $T_{1} \leq$ $T_{2} \leq \cdots \leq T_{N}$, this estimate is calculated as

$\widehat{S}(t)=\prod_{T_{i}<t} \frac{n_{i}-b_{i}}{n_{i}}$,

where $n_{i}$ is the number of surviving firms net of the number of firms lost due to censoring just prior to time $t$, and $b_{i}$ is the number of

\footnotetext{
${ }^{25}$ Since the number of firms in the Rhaeto-Romanic region is very small, we use the five main regions to associate each firm with the relevant official language.
} 
bankruptcies. ${ }^{26}$ Based on the total of 74,572 firms observed at the beginning of the survey period, Figure 1 shows the Kaplan-Meier survival estimates for firms located in (1) central municipalities, (2) touristic municipalities, and (3) other municipalities.

Figure 1 indicates that, in all three groups, more than $70 \%$ of the firms experience lifetimes of more than 123 quarters (see Table 4). This is not surprising because our sample arguably over-represents firms with larger longevity due to delayed entry. In addition, firms in touristic municipalities appear to survive longer than those in central and other municipalities.

\subsection{Modeling bankruptcy rates}

We take two different approaches towards modeling bankruptcy rates. First, we employ a continuous-time Cox proportional hazards model, which is arguably the most popular approach towards modeling bankruptcy rates. Second, we adopt Jenkins' (1995) socalled "easy estimation method" for discrete-time duration models to control for unobserved heterogeneity at the firm level (e.g., regarding the ability of a firm's management). ${ }^{27}$ That is, we reorganize the data such that spells at risk rather than individual firms are the unit of analysis, leading to several observations per firm. We then estimate a discrete-time logit hazard model with random effects.

\subsubsection{Cox proportional hazards model}

The hazard function $h_{i}(t)=f_{i}(t) / S_{i}(t)$ denotes, somewhat loosely, the rate at which firm $i$ goes bankrupt at time $t$, given that it has survived up to time $t$. Allowing for time-varying covariates, the hazard function is given by

$h_{i}\left(t \mid \mathbf{x}_{i}(t)\right)=\lim _{\mathrm{d} t \rightarrow 0} \frac{\operatorname{Pr}\left(T_{i} \in[t, t+\mathrm{d} t] \mid T_{i} \geq t,\left\{\mathbf{x}_{i}(u)\right\}_{u=0}^{t}\right)}{\mathrm{d} t}$,

where $\left\{\mathbf{x}_{i}(u)\right\}_{u=0}^{t}$ denotes the time path of firm $i$ 's vector of observed covariates (Van den Berg 2001).

According to the Cox $(1972,1975)$ proportional hazards model, the hazard function is specified as

\footnotetext{
$\overline{26}$ See Kiefer (1988) for further details.

$27 \mathrm{We}$ are grateful to the editor and one of the referees for suggesting this approach.
}

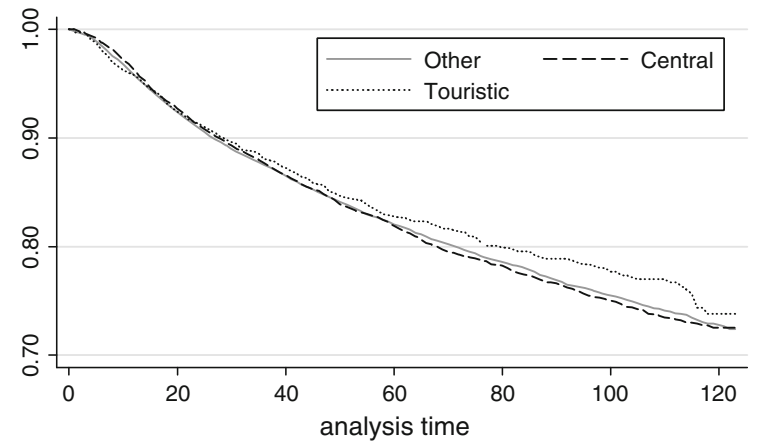

Fig. 1 Kaplan-Meier survival estimates

$h_{i}\left(t \mid \mathbf{x}_{i}(t)\right)=h_{0}(t) \exp \left(\mathbf{x}_{i}^{\prime}(t) \boldsymbol{\beta}\right)$,

where $h_{0}(t)$ is an unspecified non-negative baseline hazard which determines the shape of the hazard function, $\exp \left(\mathbf{x}_{i}^{\prime}(t) \boldsymbol{\beta}\right)$ is the systematic part of the hazard, and $\boldsymbol{\beta}$ is the coefficient vector. The latter can be estimated consistently by maximizing a partial likelihood function that does not depend on the baseline hazard (Kalbfleisch and Prentice 1980; Van den Berg 2001).

Note that we report the estimated hazard ratios $\widehat{H}_{j}=\exp \left(\widehat{\beta}_{j}\right), j=1, \ldots, p$, rather than the estimated coefficients $\widehat{\beta}_{j}$. The hazard ratio is the factor by which the hazard function is multiplied if the covariate $x_{j}$ increases by one unit. That is, if $\widehat{H}_{j}=$ 1, the hazard rate does not change in response to a change in covariate $j$, whereas the hazard rate increases (decreases) if $\widehat{H}_{j}>1\left(\widehat{H}_{j}<1\right.$, respectively).

\subsubsection{Logit model}

To control for unobserved heterogeneity at the firm level (e.g., regarding the ability of a firm's management), we employ Jenkins' (1995) “easy estimation method" for discrete-time duration models. ${ }^{28}$ This method involves (1) reorganizing the dataset such that spells at risk rather than individual firms are the unit of analysis, (2) selecting the relevant spells, and (3) estimating the hazard rate model using the

\footnotetext{
$\overline{28}$ To check for robustness, we have also employed a generalized estimating equation (GEE, see Hardin and Hilbe 2007). The results (available on request from the authors) are very similar to those reported in Tables 5 and 6 .
} 
reorganized dataset. We estimate the following random effects logistic regression,

$\log \left[\frac{h_{i}\left(t \mid \mathbf{x}_{i}(t)\right)}{1-h_{i}\left(t \mid \mathbf{x}_{i}(t)\right)}\right]=h_{0}(t)+\mathbf{x}_{i}^{\prime}(t) \boldsymbol{\beta}+\varepsilon_{i}$,

where $h_{0}(t)$ is the baseline hazard, and $\varepsilon_{i}$ is an unobserved individual-specific error term which we assume to be normally distributed with mean zero. Again, we report the estimated hazard (or odds) ratios $\widehat{H}_{j}=\exp \left(\widehat{\beta}_{j}\right), j=1, \ldots, p$, rather than the estimated coefficients $\widehat{\beta}_{j}$.

\subsection{Results}

\subsubsection{Basic specification}

Table 5 reports the results from estimating a basic specification of the Cox and the Logit model, respectively. This basic specification contains the literature's standard variables-such as firm size, age, legal form, and variables controlling for the macroeconomic conditions - and cantonal dummies describing geographic location. In addition, the basic specification controls for a firm's export activity, which is crucial for a small open economy. Since the estimation results for the Cox and the Logit model are very similar, we discuss the results for both models together.

\subsubsection{Standard variables Table 5 indicates that} there is an inverted U-shaped relation between a firm's size and its bankruptcy rate. More specifically, we find that the risk of bankruptcy increases for very small firms (up to roughly 5 employees) and then decreases monotonically, which is in line with the bulk of the exit literature (see, for example, Agarwal and Audretsch 2001) and previous evidence from Switzerland (Buehler et al. 2006). The natural log of the number of trainees, which we further include as a proxy for firm size, supports this finding: the higher the number of trainees, the lower the bankruptcy risk. Another well-known determinant of firm survival is firm age (see, for example, Freeman et al. 1983). Using the natural log of a firm's age at the time of entering the survey, we find that bankruptcy rates decrease with firm age. This is in line with Mata and Portugal (1994) and Audretsch et al. (2000). Regarding legal form, our estimates indicate that stock corporations and limited liability firms exhibit bankruptcy rates that are three- and fourfold higher than those of partnerships (the reference form). This finding is consistent with the notion that the owners of corporate companies are less risk averse and typically postpone exit until they are forced to leave the market-which increases (decreases) the likelihood of bankruptcy (voluntary liquidation). This effect is likely to be reinforced by the possible separation of ownership and management. ${ }^{29}$

\subsubsection{Export orientation and macroeconomic} conditions Our results indicate that exporting firms tend to have lower bankruptcy rates than nonexporting firms (the reference group), which is consistent with Melitz (2003) and Melitz and Ottaviano (2008). More specifically, the bankruptcy rates of firms exporting less than one-third or more than two-thirds of their sales are roughly $20 \%$ lower than those of non-exporting firms (the reference group), whereas the bankruptcy rates of firms with intermediate export share do not significantly differ from those of non-exporting firms.

To control for the macroeconomic conditions, we use the external value of the Swiss currency and the number of bankruptcies in the previous year. Here, the Logit model shows that an appreciation of the Swiss currency by one unit increases bankruptcy rates by roughly $8 \%$, as it both decreases the competitiveness of Swiss firms in foreign markets and increases the competitiveness of foreign firms in Swiss markets. Note that according to the Logit model, the lagged number of bankruptcies significantly affects the bankruptcy hazard, whereas the Cox model does not show a significant effect.

5.3.1.3 Geography In the basic specification, we use cantonal dummies to control for firm location, with the canton of Zurich serving as the reference region. ${ }^{30}$ The estimates confirm that there is considerable variation in exit rates across regions, but the evidence with respect to Hypotheses 1-4 in Table 1 is inconclusive. To see this, first consider Hypothesis 1. Clearly, bankruptcy rates vary significantly across agglomerations: bankruptcy

\footnotetext{
${ }^{29}$ See Schary (1991) for a theoretical analysis.

${ }^{30}$ We had to aggregate the cantons of Berne and Jura as well as Appenzell IR and Appenzell $A R$ to assure a sufficient number of observations in each geographic area.
} 
Table 5 Basic specification

\begin{tabular}{|c|c|c|c|c|}
\hline \multirow[t]{2}{*}{ Variable } & \multicolumn{2}{|l|}{ Cox model } & \multicolumn{2}{|l|}{ Logit model } \\
\hline & $\widehat{H}_{j}=\exp \left(\widehat{\beta}_{j}\right)$ & Clustered SE & $\widehat{H}_{j}=\exp \left(\widehat{\beta}_{j}\right)$ & $\mathrm{SE}$ \\
\hline \multicolumn{5}{|l|}{ Size, training, and age } \\
\hline LnEmp & $1.285^{* * *}$ & 0.054 & $1.314 * * *$ & 0.047 \\
\hline$(L n E m p)^{2}$ & $0.928 * * *$ & 0.009 & $0.920 * * *$ & 0.012 \\
\hline LnTrainees & $0.843 * * *$ & 0.038 & $0.823 * * *$ & 0.050 \\
\hline LnAge & $0.861 * * *$ & 0.034 & $0.813 * * *$ & 0.015 \\
\hline \multicolumn{5}{|l|}{ Legal form } \\
\hline Stock Corp & $3.064 * * *$ & 0.220 & $3.411 * * *$ & 0.077 \\
\hline Lim Liab & $4.025 * * *$ & 0.333 & $4.437 * * *$ & 0.091 \\
\hline \multicolumn{5}{|l|}{ Export orientation } \\
\hline Exposh_2 & $0.791 * * *$ & 0.041 & $0.776 * * *$ & 0.058 \\
\hline Exposh_3 & 0.960 & 0.073 & 0.969 & 0.085 \\
\hline Exposh_4 & $0.781 * * *$ & 0.050 & $0.767 * * *$ & 0.070 \\
\hline \multicolumn{5}{|c|}{ Macroeconomic conditions } \\
\hline Bankrupt & 1.002 & 0.004 & $1.066 * * *$ & 0.003 \\
\hline Ext Value & $1.058 * * *$ & 0.004 & $1.083 * * *$ & 0.004 \\
\hline \multicolumn{5}{|l|}{ Cantons } \\
\hline Bern (with Jura) & $1.116^{*}$ & 0.069 & $1.134 *$ & 0.068 \\
\hline Luzern & 1.058 & 0.097 & 1.054 & 0.102 \\
\hline Uri & 0.750 & 0.307 & 0.717 & 0.442 \\
\hline Schwyz & 0.975 & 0.129 & 0.961 & 0.147 \\
\hline Obwalden & 1.042 & 0.293 & 1.043 & 0.308 \\
\hline Nidwalden & 0.718 & 0.152 & 0.692 & 0.229 \\
\hline Glarus & 0.984 & 0.258 & 0.996 & 0.287 \\
\hline Zug & 1.003 & 0.095 & 0.995 & 0.105 \\
\hline Fribourg & $1.321 * * *$ & 0.117 & $1.352 * * *$ & 0.100 \\
\hline Solothurn & $1.349 * * *$ & 0.135 & $1.387 * * *$ & 0.112 \\
\hline Basel-Stadt & 1.081 & 0.109 & 1.085 & 0.113 \\
\hline Basel-Landschaft & $1.218^{* *}$ & 0.111 & $1.236 * *$ & 0.102 \\
\hline Schaffhausen & 0.796 & 0.156 & 0.778 & 0.213 \\
\hline Appenzell $(I R+A R)$ & $0.694 *$ & 0.142 & $0.676^{*}$ & 0.219 \\
\hline St. Gallen & 1.090 & 0.082 & 1.094 & 0.084 \\
\hline Graubuenden & 0.861 & 0.114 & 0.837 & 0.146 \\
\hline Aargau & 1.119 & 0.081 & $1.142 *$ & 0.080 \\
\hline Thurgau & $1.274 * * *$ & 0.120 & $1.304 * *$ & 0.106 \\
\hline Ticino & $1.345^{* * *}$ & 0.088 & $1.371 * * *$ & 0.074 \\
\hline Vaud & $1.469 * * *$ & 0.087 & $1.545 * * *$ & 0.066 \\
\hline Valais & $1.330 * * *$ & 0.131 & $1.380 * * *$ & 0.106 \\
\hline Neuchâtel & $1.560 * * *$ & 0.158 & $1.634 * * *$ & 0.116 \\
\hline Genève & $1.300 * * *$ & 0.085 & $1.310 * * *$ & 0.073 \\
\hline Constant & & & $3.71 \mathrm{E}-08 * * *$ & 0.421 \\
\hline
\end{tabular}


Table 5 continued

Dummy coding: Legal form, Partnership (ref. variable); Export orientation, Export_1 (no exports) (ref. variable); Cantons, Zurich (ref. variable)

SE Standard error

$*, * *, * * *$ Coefficients are significant at 10,5 , and $1 \%$, respectively

\begin{tabular}{|c|c|c|c|c|}
\hline \multirow[t]{2}{*}{ Variable } & \multicolumn{2}{|l|}{ Cox model } & \multicolumn{2}{|l|}{ Logit model } \\
\hline & $\widehat{H}_{j}=\exp \left(\widehat{\beta}_{j}\right)$ & $\begin{array}{l}\text { Clustered } \\
\text { SE }\end{array}$ & $\widehat{H}_{j}=\exp \left(\widehat{\beta}_{j}\right)$ & SE \\
\hline \multicolumn{5}{|l|}{ Statistics } \\
\hline $\mathcal{X}^{2}$ (all variables) & 751.85 & & $1,610.99$ & \\
\hline Log likelihood & $-40,117.20$ & & $-23,038.83$ & \\
\hline Number of observations/groups & 68,681 & & 68,681 & \\
\hline $\begin{array}{l}\text { Number of observations per } \\
\text { group (min./avg./max.) }\end{array}$ & & & $1 / 6.7 / 33$ & \\
\hline
\end{tabular}

rates in the canton of Zurich (the reference canton), with the country's largest agglomeration and international airport, respectively, are significantly lower than those in other-less agglomeratedcantons. ${ }^{31}$ Yet, bankruptcy rates in the canton of Geneva, with the second-largest agglomeration and international airport, are significantly higher than those in less agglomerated cantons (e.g., Uri, Schwyz, Nidwalden, and Glarus). This is clearly inconsistent with Hypothesis 1a. Moreover, business conditions (cf. Hypothesis 2) are well known to vary considerably across cantons, and the cantonal dummies do not properly reflect this variation. Similar qualifications hold regarding Hypotheses 3 and 4: the estimated hazard ratios suggest that bankruptcy rates tend to be higher in French- and Italian-speaking cantons, but the pattern is not consistent. Moreover, the role of religion in explaining bankruptcy rates remains unclear. To shed further light on Hypotheses 1-4, we next consider a refined specification.

\subsubsection{Refined specification}

The refined specification of the Cox and the Logit model differs from the basic specification in the following respects:

(i) We control for the industry in which a firm operates. More specifically, we use the equivalent of the two-digit SIC code for Switzerland to control for industry-specific effects.

\footnotetext{
31 Inspection of the estimated hazard ratios indicates that bankruptcy rates in the cantons of Neuchâtel, Valais, Vaud, Ticino, Thurgau, Solothurn, and Fribourg are more than $30 \%$ higher than those in Zurich.
}

(ii) To characterize a firm's geographic environment, we use the main municipality types listed in Table 2. In addition, we control for differences in economic policy, using local tax levels, public spending, public investment, local unemployment, and growth (measured at the cantonal level). Moreover, we control for the composition of the local population at the cantonal level.

(iii) We use the joint share of the dominating religious denominations as well as the official language to proxy for local cultural characteristics.

Table 6 reports the estimation results for the refined specification. Again, we discuss the results for the Cox and the Logit model together.

5.3.2.1 Standard variables We first note that the estimated hazard ratios for the standard variables remain largely unchanged relative to the basic specification. That is, the estimates with respect to firm size, age, legal form, export orientation, and macroeconomic conditions remain similar to the basic specification and are in line with the previous literature. In particular, we still find that the risk of bankruptcy tends to be decreasing in firm size and age. A relevant difference concerns the estimated impact of export orientation: firms exporting more than twothirds of their turnover are no longer estimated to have significantly lower exit rates than non-exporting firms.

As to the industry-specific effects, it should be noted that bankruptcy rates are highest for food \& textiles (reference industry), construction, and restaurants. Bankruptcy rates are lowest in industries where public administration or regulation plays an important role, such as waste treatment, research and development, education, and banking. In these 
Table 6 Refined specification

\begin{tabular}{|c|c|c|c|c|}
\hline \multirow[t]{2}{*}{ Variable } & \multicolumn{2}{|l|}{ Cox model } & \multicolumn{2}{|l|}{ Logit model } \\
\hline & $\widehat{H}_{j}=\exp \left(\widehat{\beta}_{j}\right)$ & Clustered SE & $\widehat{H}_{j}=\exp \left(\widehat{\beta}_{j}\right)$ & $\mathrm{SE}$ \\
\hline \multicolumn{5}{|l|}{ Size, training and age } \\
\hline LnEmp & $1.161 * * *$ & 0.049 & $1.167 * * *$ & 0.044 \\
\hline$(L n E m p)^{2}$ & $0.939 * * *$ & 0.010 & $0.936 * * *$ & 0.011 \\
\hline Trainees & $0.836 * * *$ & 0.039 & $0.828 * * *$ & 0.047 \\
\hline LnAge & $0.827 * * *$ & 0.033 & $0.821 * * *$ & 0.014 \\
\hline \multicolumn{5}{|l|}{ Legal form } \\
\hline Stock Corp & $3.374 * * *$ & 0.250 & $3.488 * * *$ & 0.074 \\
\hline Lim Liab & $4.212 * * *$ & 0.355 & $4.239 * * *$ & 0.085 \\
\hline \multicolumn{5}{|l|}{ Export orientation } \\
\hline Exposh_2 & $0.884 * *$ & 0.048 & $0.885 * *$ & 0.055 \\
\hline Exposh_3 & 1.081 & 0.085 & 1.090 & 0.080 \\
\hline Exposh_4 & 0.900 & 0.060 & 0.901 & 0.068 \\
\hline \multicolumn{5}{|c|}{ Macroeconomic conditions } \\
\hline Bankrupt & 1.008 & 0.005 & $1.064 * * *$ & 0.005 \\
\hline Ext Value & $1.060 * * *$ & 0.004 & $1.085 * * *$ & 0.004 \\
\hline \multicolumn{5}{|l|}{ Industry structure } \\
\hline Leather & 0.865 & 0.129 & 0.865 & 0.154 \\
\hline Chemicals & $0.646 * *$ & 0.125 & $0.636 * *$ & 0.196 \\
\hline Metals & $0.738^{*}$ & 0.117 & $0.734 *$ & 0.163 \\
\hline Machines & $0.706 * *$ & 0.106 & $0.706 * *$ & 0.154 \\
\hline Vehicles & 0.819 & 0.256 & 0.808 & 0.326 \\
\hline Furniture & 0.950 & 0.185 & 0.956 & 0.199 \\
\hline Utilities & 0.564 & 0.227 & 0.563 & 0.408 \\
\hline Construct & 1.167 & 0.161 & 1.173 & 0.142 \\
\hline Veh Trade & $0.753 *$ & 0.114 & $0.743 *$ & 0.156 \\
\hline Wholesale & $0.617 * * *$ & 0.086 & $0.611 * * *$ & 0.143 \\
\hline Retail & 0.865 & 0.120 & 0.865 & 0.143 \\
\hline Restaurant & 1.260 & 0.187 & 1.278 & 0.153 \\
\hline Traffic & 0.787 & 0.122 & 0.782 & 0.159 \\
\hline Banks & $0.468 * * *$ & 0.092 & $0.459 * * *$ & 0.201 \\
\hline Real estate & $0.578 * * *$ & 0.098 & $0.571 * * *$ & 0.175 \\
\hline Data & $0.554 * * *$ & 0.087 & $0.558 * * *$ & 0.160 \\
\hline$R \& D$ & $0.427 *$ & 0.196 & $0.422 *$ & 0.474 \\
\hline Consulting & $0.518 * * *$ & 0.072 & $0.514 * * *$ & 0.142 \\
\hline Education & $0.449 * * *$ & 0.119 & $0.446 * * *$ & 0.270 \\
\hline Health & $0.493 * * *$ & 0.116 & $0.493 * * *$ & 0.242 \\
\hline Waste & $0.226 * * *$ & 0.134 & $0.219 * *$ & 0.598 \\
\hline Other & $0.729 * *$ & 0.115 & $0.728 * *$ & 0.163 \\
\hline \multicolumn{5}{|l|}{ Population } \\
\hline Migration Balance & 0.935 & 0.061 & 0.959 & 0.067 \\
\hline Foreigner & $0.967 * * *$ & 0.008 & $0.965 * * *$ & 0.008 \\
\hline PopAge & $0.907 * * *$ & 0.021 & $0.899 * * *$ & 0.024 \\
\hline \multicolumn{5}{|l|}{ Culture } \\
\hline DomRel & $0.985 * * *$ & 0.003 & $0.984 * * *$ & 0.004 \\
\hline
\end{tabular}


Table 6 continued

Dummy coding: Legal form, Partnership (ref. variable);

Export orientation, Export_1 (no exports) (ref. variable); Industries, Food (ref. variable); Culture, German (ref. variable), OtherRel (ref. variable); Municipality types, Center (ref. variable) $*, * *, * * *$ Coefficients are significant at 10,5 , and $1 \%$, respectively

\begin{tabular}{|c|c|c|c|c|}
\hline \multirow[t]{2}{*}{ Variable } & \multicolumn{2}{|l|}{ Cox model } & \multicolumn{2}{|l|}{ Logit model } \\
\hline & $\widehat{H}_{j}=\exp \left(\widehat{\beta}_{j}\right)$ & Clustered SE & $\widehat{H}_{j}=\exp \left(\widehat{\beta}_{j}\right)$ & SE \\
\hline French & 0.910 & 0.098 & 0.890 & 0.110 \\
\hline Italian & 1.167 & 0.158 & 1.162 & 0.141 \\
\hline \multicolumn{5}{|l|}{ Business conditions } \\
\hline Private taxes & 0.998 & 0.002 & 0.999 & 0.002 \\
\hline Corporate taxes & $1.004 *$ & 0.002 & $1.004 * *$ & 0.002 \\
\hline Public spend & 1.023 & 0.019 & 1.029 & 0.020 \\
\hline Public invest & 0.914 & 0.058 & $0.887 *$ & 0.065 \\
\hline Unemployment & $1.190 * * *$ & 0.035 & $1.208 * * *$ & 0.030 \\
\hline Growth & $0.989 * * *$ & 0.005 & 0.993 & 0.005 \\
\hline \multicolumn{5}{|l|}{ Municipality types } \\
\hline Suburban & $1.146 * * *$ & 0.049 & $1.156^{* * *}$ & 0.043 \\
\hline Affluent & 0.865 & 0.078 & 0.866 & 0.092 \\
\hline Periurban & 0.957 & 0.071 & 0.960 & 0.075 \\
\hline Touristic & $0.660 * * *$ & 0.087 & $0.653 * * *$ & 0.132 \\
\hline Industrial \& tertiary & 0.990 & 0.067 & 0.997 & 0.072 \\
\hline Rural & 0.951 & 0.094 & 0.946 & 0.099 \\
\hline Agrarian mixed & 0.936 & 0.102 & 0.937 & 0.112 \\
\hline Agrarian & 0.703 & 0.200 & 0.713 & 0.289 \\
\hline Constant & & & $1.158 \mathrm{E}-05 * * *$ & 1.169 \\
\hline \multicolumn{5}{|l|}{ Statistics } \\
\hline $\mathcal{X}^{2}$ (all variables) & $1,126.37$ & & $2,025.28$ & \\
\hline Log likelihood & $-39,527.11$ & & $-22,638.52$ & \\
\hline Number of observations/groups & 67,944 & & 67,944 & \\
\hline $\begin{array}{l}\text { Number of observations per } \\
\text { group (min./avg./max.) }\end{array}$ & & & $1 / 6.7 / 33$ & \\
\hline
\end{tabular}

industries, bankruptcy rates are more than 50\% lower than those in food and textiles. We also find that bankruptcy rates are significantly lower if the average age of the population or the share of foreign population is high. The latter finding may indicate that bankruptcy rates tend to be low in regions where business conditions have been favorable in the past, thereby attracting (foreign) labor.

We now consider each of our above hypotheses in turn.

Hypothesis 1: Agglomeration economies In the refined specification, we use the main municipality types to control for the characteristics of a firm's geographic environment. Let us first consider the hypothesis that bankruptcy rates are lowest in the central municipalities of agglomerations (Hypothesis 1b). Inspection of Table 6 indicates that bankruptcy rates are lowest in touristic municipalities and highest in suburban municipalities. Specifically, we find that bankruptcy rates in touristic municipalities are more than $30 \%$ lower than those in central municipalities (the reference group), whereas they are roughly $15 \%$ higher in suburban municipalities. For all other municipality types, bankruptcy rates do not significantly deviate from those in central municipalities. Since touristic municipalities often form the center of smaller non-metropolitan agglomerations (St. Moritz is a case in point), it is fair to conclude that bankruptcy rates tend to be lower in the central municipalities of (metropolitan and non-metropolitan) agglomerations.

Hypothesis 2: Business conditions Next, we consider the hypothesis that bankruptcy rates are lower in regions with favorable business conditions. Our estimates indicate that the (lagged) local unemployment rate has a strong and significant positive 
impact on bankruptcy rates, which is in line with Hypothesis 2a. Similarly, we find that the level of corporate taxes has a significant positive impact on bankruptcy rates, which corroborates Hypothesis $2 b$. The level of private taxes, in turn, does not significantly affect bankruptcy rates. A relevant difference between the Cox and the Logit model concerns another aspect of favorable business conditions: The Logit model suggests that the level of public investment has a significant negative impact on bankruptcy rates (Hypothesis 2c), whereas local growth is not a significant determinant of bankruptcy rates. The Cox model reverses the roles of these variables in terms of significance.

Overall, our results support the notion that bankruptcy rates are lower in regions with favorable business conditions, with the qualification that favorable business conditions are mostly characterized by low corporate taxes and unemployment and high public investment. These findings are in line with Lane and Schary (1991) and Love (1996a, b).

Hypothesis 3: Religion Next, consider the hypothesis that bankruptcy rates are lower in religious regions. ${ }^{32}$ Even though the joint share of the dominating religious denominations is arguably a crude proxy, we find that it has a significant negative impact on bankruptcy rates in both models: a $1 \%$ increase of this share is associated with a reduction in bankruptcy rates by roughly $2 \%$, which is consistent with Hypothesis 3. However, this result should be interpreted carefully. Inspection of Table 3 indicates that the share of the dominating religious denominations varies strongly across linguistic regions, such that it is difficult to disentangle the impact of religion and language on bankruptcy rates.

Hypothesis 4: Language Finally, we examine the differences in bankruptcy rates across linguistic regions. While the basic specification suggests that bankruptcy rates in French- and Italian-speaking cantons tend to be higher than those in Germanspeaking cantons, we do not find a significant impact of language on bankruptcy rates in the refined specification. This is in line with Hypothesis 4.

\footnotetext{
32 Recall that, according to the Weberian perspective, bankruptcy rates should be lower in religious regions because firms employ more productive workers with strong work ethic and drift.
}

However, using French rather than German as the reference variable, we find significantly higher bankruptcy rates in Italian-speaking regions, which is inconsistent with Hypothesis $4 .{ }^{33}$ As noted above, the result needs to be interpreted carefully because it is difficult to disentangle the role of religion and language.

\section{Conclusion}

Starting from the idea that focusing on standard economic determinants alone might lead to an incomplete understanding of important economic phenomena such as bankruptcy, we have analyzed the role of geography in explaining firm bankruptcy. To do so, we have used a comprehensive database from Switzerland, which (1) allows us to characterize each firm's geographic location and (2) reflects the well-known ethnic and cultural diversity of the country.

Employing various hazard rate models, we have established the following results. First, bankruptcy rates tend to be lower in the central municipalities of (metropolitan and non-metropolitan) agglomerations. Second, bankruptcy rates are lower in regions with favorable business conditions where corporate taxes and unemployment are low and public investment is high. Third, private taxation and public investment at the local level have little (if any) impact on bankruptcy rates.

Our results indicate that geography plays an important role in explaining firm bankruptcy. This role has found little attention in previous work. We believe that analyzing the role of geography in explaining economic outcomes such as bankruptcy is a promising avenue for future research.

Acknowledgments We are grateful to the associate editor, Philipp Koellinger, and three anonymous referees for many detailed comments. We also thank Dirk Burghardt, Manfred Fischer, Bruno Frey, Dennis Gärtner, Luigi Guiso, Daniel Halbheer, Ulrich Kaiser, Mariko Klasing, Rico Maggi, Gianmarco Ottaviano, Dieter Pennerstorfer, Armin Schmutzler, Enrique Schroth, Christoph Weiss, and seminar participants at Arlington (IIOC 2008), Berne (Swiss IO Day 2006), Brussels (EcoMod), Lugano, Milan (EEA 2008), Munich (VfS 2007), Valencia (EARIE 2007), and Zurich for helpful discussions and suggestions. Support from the Swiss National Science Foundation (through grant no. PP0012114754), the Swiss Federal Statistical Office, and the

\footnotetext{
$\overline{33}$ These estimates are available on request from the authors.
} 
Cantonal Bank of St. Gallen is gratefully acknowledged. The usual disclaimer applies. In particular, the opinions expressed in this paper are those of the authors and are not attributable to HSBC. The authors are solely responsible for the contents.

\section{References}

Agarwal, R., \& Audretsch, D. (2001). Does entry size matter? The impact of the life cycle and technology on firm survival. Journal of Industrial Economics, 49, 21-43.

Agarwal, R., \& Gort, M. (1996). The evolution of markets and entry, exit and survival of firms. Review of Economics and Statistics, 78, 489-498.

Alcácer, J., \& Chung, W. (2007). Location strategies and knowledge spillovers. Managment Science, 53, 760-776.

Audretsch, D. B. (1995). Innovation and industry evolution. Cambridge, MA: MIT Press.

Audretsch, D. B., Houweling, P., \& Thurik, A. R. (2000). Firm survival in the Netherlands. Review of Industrial Organization, 16, 1-11.

Audretsch, D. B., Bönte, W., \& Tamvada, J. P. (2007). Religion and entrepreneurship. CEPR Discussion Paper No. 6378.

Berglund, E., \& Brännäs, K. (2001). Plants's entry and exit in Swedish municipalities. Annals of Regional Science, 35, 431-448.

Boschma, R. A., \& Wenting, R. (2007). The spatial evolution of the British automobile industry: Does location matter? Industrial and Corporate Change, 16, 213-238.

Brüderl, J., \& Schüssler, R. (1990). Organizational mortality: The liabilities of newness and adolescence. Administrative Science Quarterly, 35, 530-547.

Brüderl, J., Preisendörfer, P., \& Ziegler, R. (1992). Survival chances of newly founded business organizations. American Sociological Review, 57, 227-242.

Buehler, S., Kaiser, C., \& Jaeger, F. (2005). Competition policy and exit rates: Evidence from Switzerland. Contributions to Economic Analysis \& Policy, 4, Article 15. Available at: http://www.bepress.com/bejeap/ contributions/vol4/iss1/art15.

Buehler, S., Kaiser, C., \& Jaeger, F. (2006). Merge or fail? The determinants of mergers and bankruptcies in Switzerland, 1995-2000. Economics Letters, 90, 88-95.

Buenstorf, G., \& Klepper, S. (2009). Heritage and agglomeration: The Akron tyre cluster revisited. Economic Journal, 119, 705-733.

Caves, R. E. (1998). Industrial organization and new findings on the turnover and mobility of firms. Journal of Economic Literature, 36, 1947-1982.

Combes, P. P., Duranton, G., Gobillon, L., \& Puga, D. (2009). The productivity advantages of large cities: Distinguishing agglomeration from firm selection. Mimeo.

Cox, D. R. (1972). Regression models and life-tables. Journal of the Royal Statistical Society, Series, B34, 187-220.

Cox, D. R. (1975). Partial likelihood. Biometrika, 62, 269-276.

Dahl, M. S., \& Sorenson, O. (2009). The embedded entrepreneur. European Management Review, 6, 172-181.
Dahl, M. S., \& Sorenson, O. (2010). Home sweet home: entrepreneurs' location choices and the performance of their ventures. Available at: http://www.ssrn.com/ abstract=1596810. Accessed 27 Apr 2010.

Dunne, T., Roberts, M. J., \& Samuelson, L. (1988). The growth and failure of U.S. manufacturing plants. Quarterly Journal of Economics, 104, 671-698.

Dunne, T., Klimek, S. D., \& Roberts, M. J. (2005). Exit from regional manufacturing markets: The role of entrant experience. International Journal of Industrial Organization, 23, 399-421.

Duranton, G., \& Puga, D. (2001). Nursery cities: Urban diversity, process innovation, and the life cycle of products. American Economic Review, 91, 1454-1477.

Duranton, G., \& Puga, D. (2004). Micro-foundations of urban agglomeration economies. In J. V. Henderson \& J. F. Thisse (Eds.), Handbook of regional and urban economics (Vol. 4, pp. 2063-2117). Amsterdam: North-Holland.

Evans, D. S., \& Leighton, L. S. (1990). Small business formations by employed and unemployed workers. Small Business Economics, 2, 319-330.

Everett, J., \& Watson, J. (1998). Small business failure and external risk factors. Small Business Economics, 11, 371-390.

Fearon, J. D. (2003). Ethnic and cultural diversity by country. Journal of Economic Growth, 8, 195-222.

Feld, L. P., \& Kirchgässner, G. (2001). Income tax competition at the state and local level in Switzerland. Regional Science and Urban Economics, 31, 181-213.

Fernández, R., \& Fogli, A. (2009). Culture: An empirical investigation of beliefs, work and fertility. American Economic Journal: Macroeconomics, 1, 146-177.

Fotopoulos, G., \& Louri, H. (2000). Location and survival of new entry. Small Business Economics, 14, 311-321.

Freeman, J., Carroll, G. R., \& Hannan, M. T. (1983). The liability of newness: Age dependence in organizational death rates. American Sociological Review, 48, 692-710.

Fujita, M., \& Krugman, P. (2004). The new economic geography: Past, present and the future. Papers in Regional Science, 83, 139-164.

Fujita, M., Krugman, P., \& Venables, A. J. (1999). The spatial economy: Cities, regions, and international trade. Cambridge, MA: MIT Press.

Geroski, P. A. (1995). What do we know about entry? International Journal of Industrial Organization, 13, 421-440.

Glaeser, E. L., Kallal H. D., Scheinkman, J. A., \& Schleifer, A. (1992). Growth in cities. Journal of Political Economy, $100,1126-1152$.

Glauben, T., Tietje, H., \& Weiss, C. (2006). Agriculture on the move: Exploring regional differences in farm exit rates in Western Germany. Jahrbuch für Regionalwissenschaft, 26, 103-118.

Gottmann, J. (1980). Center and periphery. London: Sage.

Guiso, L., Sapienza, P., \& Zingales, L. (2006). Does culture affect economic outcomes? Journal of Economic Perspectives, 20, 23-48.

Guiso, L., Sapienza, P., \& Zingales, L. (2009). Cultural biases in economic exchange? Quarterly Journal of Economics, 124, 1095-1131.

Hardin, J., \& Hilbe, J. (2007). Generalized linear models and extensions (2nd ed.). College Station, TX: Stata Press. 
Harhoff, D., Stahl, K., \& Woywode, M. (1998). Legal form, growth and exit of West German firms-empirical results for manufacturing, construction, trade and service industries. Journal of Industrial Economics, 46, 453-488.

Hudson, J. (1989). The birth and death of firm. Quarterly Review of Economics and Business, 29, 68-86.

Jacobs, J. (1969). The economics of cities. New York: Vintage.

Jenkins, S. J. (1995). Easy estimation methods for discrete-time duration models. Oxford Bulletin of Economics and Statistics, 57, 129-138.

Kalbfleisch, J. D., \& Prentice, R. L. (1980). The statistical analysis of failure time data. New York: Wiley.

Kiefer, N. M. (1988). Economic duration data and hazard functions. Journal of Economic Literature, 26, 646-679.

Klepper, S. (2007). Disagreements, spinoffs, and the evolution of Detroit as the capital of the U.S. automobile industry. Management Science, 53, 616-631.

Klepper, S., \& Thompson, S. (2007). Spin-off entry in hightech industries: Motives and consequences. In F. Malerba \& S. Brusoni (Eds.), Perspectives on innovation (pp. 187-218). Cambridge: Cambridge University Press.

Krueger, J. J., \& von Rhein, K. (2009). Knowledge, profitability and exit of German car manufacturing firms. Economics of Innovation and New Technology, 18, 107-122.

Lane, S. J., \& Schary, M. (1991). Understanding the business failure rate. Contemporary Policy Issues, 9, 93-105.

Love, J. H. (1996a). The determinants of variations in exit rates. Empirica, 23, 107-118.

Love, J. H. (1996b). Entry and exit: A county-level analysis. Applied Economics, 28, 441-451.

Mata, J., \& Portugal, P. (1994). Life duration of new firms. Journal of Industrial Economics, 42, 227-245.

Mata, J., Portugal, P., \& Guimarães, P. (1995). The survival of new plants: Start-up conditions and post-entry evolution. International Journal of Industrial Organization, 13, 459-481.

McCleary, R., \& Barro, R. J. (2006). Religion and economy. Journal of Economic Perspectives, 20, 49-72.

Melitz, M. J. (2003). The impact of trade on intra-industry reallocations and aggregate industry productivity. Econometrica, 71, 1695-1725.

Melitz, M. J., \& Ottaviano, G. I. P. (2008). Market size, trade, and productivity. Review of Economic Studies, 75, 295-316.

Melo, P. C., Graham, D. J., \& Noland, R. B. (2009). A metaanalysis of estimates of urban agglomeration economies. Regional Science and Urban Economics, 39, 332-342.

Neffke, F., Henning, M. S., Boschma, R., Lundquist, K. J., \& Olander, L. O. (2010). The dynamics of agglomeration externalities along the life cycle of industries. Regional Studies, 44, 1-17.

Puga, D. (2010). The magnitude and causes of agglomeration economies. Journal of Regional Science, 50, 203-219.

Ranger-Moore, J. (1997). Bigger may be better but is older wiser? Organizational age and size in the New York life insurance industry. American Sociological Review, 62, 903-920.

Roberts, B. M., \& Thompson, S. (2003). Entry and exit in a transition economy: The case of Poland. Review of Industrial Organization, 22, 225-243.

Rosenthal, S. S., \& Strange, W. C. (2004). Evidence on the nature and sources of agglomeration economies. In $\mathrm{V}$. Henderson \& J. F. Thisse (Eds.), Handbook of regional and urban economics (Vol. 4, pp. 2119-2171). Amsterdam: North-Holland.

Schary, M. A. (1991). The probability of exit. RAND Journal of Economics, 22, 339-353.

Segarra, A., \& Callejón, M. (2002). New firms' survival and market turbulence: New evidence from Spain. Review of Industrial Organization, 20, 1-14.

Shaver, J. M., \& Flyer, F. (2000). Agglomeration economies, firm heterogeneity, and foreign direct investment in the United States. Strategic Management Journal, 21, 1175-1193.

Sorenson, O., \& Audia P. G. (2000). The social structure of entrepreneurial activity: Geographic concentration of footwear production in the United States, 1940-1989. American Journal of Sociology, 106, 424-461.

Swiss Federal Statistical Office. (2004). Religionslandschaft in der Schweiz. (The religious landscape of Switzerland). Neuchâtel: Swiss Federal Statistical Office.

Swiss Federal Statistical Office. (2005). Die Raumgliederung der Schweiz. (The spatial structures of Switzerland). Neuchâtel: Swiss Federal Statistical Office.

Symeonidis, G. (2002). The effects of competition. Cambridge, MA: MIT Press.

Tabellini, G. (2008). Institutions and culture. Journal of the European Economic Association, 6, 255-294.

Van den Berg, G. J. (2001). Duration models: Specification, identification, and multiple durations. In J. J. Heckman \& E. Leamer (Eds.), Handbook of econometrics (Vol. V, pp. 3381-3460). Amsterdam: North Holland.

Van Kranenburg, H. L., Palm, F. C., \& Pfann, G. A. (2002). Exit and survival in a concentrating industry: The case of daily newspapers in the Netherlands. Review of Industrial Organization, 21, 283-303. 